\title{
Eyewitness Testimony in Occupational Accident Investigations: Towards a Research Agenda
}

\author{
E. Kevin Kelloway, ${ }^{1,2}$ Veronica Stinson, ${ }^{1}$ and Carla MacLean ${ }^{1}$
}

Accident investigation is frequently cited as the cornerstone of an effective occupational health and safety program. We suggest that the literature on accident investigation is based on a model of witnesses as neutral and accurate recording devices. The literature on eyewitness testimony and criminal investigation offers strikingly different conclusions. We review these findings and point to their implication for research on accident investigation in occupational health and safety contexts.

KEY WORDS: eyewitness testimony; accident investigation.

Two employees were moving stock in a furniture warehouse. Both were experienced employees who have rearranged stock hundreds of times. Large appliances were stacked four high on pallets. One of the clothes dryers on the top tier began to fall. Attempting to catch the appliance before it smashed to the floor, one employee suffered severe muscle damage to his back and shoulder. As a result of the injury, the employee is unable to return to his regular employment. The state-sponsored Workers' Compensation fund has awarded him a long-term pension and is now paying for his retraining into a more suitable occupation. The employer is paying increased Workers' Compensation premiums for the foreseeable future. The employee is paying with the loss of his career and his health. All parties have lost as a result of the incident.

This brief description illustrates many of the central features of occupational accidents. For purposes of exposition, we highlight three of these features. First, although the outcome of the incident is clear in terms of both physical and economic consequences, exactly what happened is not clear. Were the appliances improperly stacked in the first place? Did the employees bump the tiers dislodging the dryer? Were other parties involved? Second, in a related vein, it is difficult to determine why the accident happened. Were the workers careless? Were they untrained? What differentiated this day from the hundreds of similar events in the past that did not

\footnotetext{
${ }^{1}$ Department of Management, Saint Mary's University, Halifax, Nova Scotia, Canada.

${ }^{2}$ To whom correspondence should be addressed at Department of Management, Saint Mary's University, Halifax, Nova Scotia, Canada B3H 3C3; e-mail: kevin.kelloway@stmarys.ca.
} 
result in an accident? Finally, most importantly for this review, in most cases, attempts to answer these questions are going to rely on interviews of eyewitnesses.

Given this emphasis on eyewitness testimony as a means to investigate and understand occupational accidents, it is perhaps surprising to note that our literature searches revealed two striking gaps. First, the literature on accident investigations is largely practitioner-based and does not reference the empirical research literature on eyewitness testimony. Rather, the overwhelming impression is that accident investigators treat eyewitnesses as neutral and accurate recording devices. Second, the empirical research literature on eyewitness testimony has focused almost exclusively on memory for criminal events and has not considered generalizing to other relevant contexts such as occupational accidents.

Our purpose in this paper is to begin to rectify both omissions. First, we establish some context by reviewing the role of accident investigations in health and safety programming. Second, we briefly summarize the literature on eyewitness testimony with a specific focus on identifying similarities and differences between accident and criminal investigations. Finally, we attempt to bridge these literatures by framing specific questions for future research. It is our belief that both field of enquiry benefit from this endeavor. Accident investigations could be designed and conducted on a strong empirical base while theories or hypotheses about eyewitness testimony could be tested in a situation analogous to criminal investigations thereby providing a basis for generalization.

\section{THE ROLE OF ACCIDENT INVESTIGATIONS IN HEALTH AND SAFETY PROGRAMS}

In 2001 (the last year in which data are available), the U.S. Bureau of Labor Statistics reported 5,900 workplace fatalities and 5.2 million occupational illnesses and injuries. Moreover, the occupational fatality rate exceeds the annual death rate attributable to breast cancer, prostate cancer, colorectal cancer, firearms, and AIDS (Leigh, Markowitz, Fah, Shin, \& Landrigan, 1997; Sauter, Hurrell, Fox, Tetrick, \& Barling, 1999). These figures become more striking when one recognizes that data on occupational injuries tend to be underreported (Conway \& Svenson, 1998; Eisenberg \& MacDonald, 1988).

In addition to the human costs of workplace fatalities and injuries, accidents exert serious negative financial effects on organizations. For example, Dupré (2000) estimated that in approximately half the accidents that occurred in the European Union in 1996, the resulting absence from work was between 2 weeks and 3 months. In United States, 80 million days of lost productivity were associated with workplace accidents in 1998 (United States Census Bureau, 2000). Leigh et al. (1997) estimated the 1992 costs of injuries conservatively at $\$ 145$ billion. In Canada the cost of each workplace injury is estimated to be $\$ 6,000$, with the cost of each workplace fatality estimated to be $\$ 492,000$ (Marshall, 1996).

Not surprisingly, human resource and safety professionals have increasingly turned toward systematic safety programming in an attempt to reduce injuries, fatalities, and costs. The conduct of an investigation after each workplace accident 
is frequently cited as a critical component of a firm's occupational health and safety program (Montgomery \& Kelloway, 2002). Such investigations are aimed at recreating the events leading up to the accident and identifying the causes of the event. The results of such investigations are used to form preventative safety policies and practices that will result in a reduced likelihood of reoccurrence.

The principal role of the accident investigation is to prevent future occurrences of a similar nature. Such investigations serve this purpose through a variety of routes including, but not limited to, the determination of direct and contributing causes, the prevention of similar accidents, the creation of a permanent record to be used in further analysis, and programming and raising safety awareness (Ferry, 1988; Laing, 1992).

Although the importance of effective investigation procedures to a health and safety program cannot be overstated, the reality of such investigation stands in stark contrast to the list of goals described above. Ferry $(1988$, p. 3 ) describes the modal pattern when he says "Most mishaps are investigated by persons without any investigative background who have no particular approach to the task. They usually have minimal resources to meet minimum company or government regulations."

The literature on accident investigations typically offers only rudimentary suggestions on interviewing techniques (e.g., Ferry, 1988; Montgomery \& Kelloway, 2002) or the provision of some broad outlines for investigation as guides to the investigators. For example, Montgomery and Kelloway (2002) follow standard practice in suggesting that investigators need to focus on three broad areas in their investigation; human factors (e.g., What was the worker doing at the time of the accident? Was he or she performing a regular task, a different task, doing maintenance work, or helping a coworker? Were the tasks or procedures new? What was the posture and location of the employee?); situational factors (e.g., What was the site/location of the accident? What tools and equipment or objects were involved in the accident? Was the correct equipment available and being used to do the job? What personal protective equipment (gloves, goggles, etc.) was being worn? Were guards in place? What time of day did the accident occur?); and environmental factors (e.g., noise, heat, light).

Indeed much of this literature is devoted to developing "models" of accident causation (e.g., Reason, 1990) that provide organizing schemas for the results of the accident investigation. Comparatively little attention is paid to the actual process of data collection. For example, in their report on accident investigation techniques, Livingston, Jackson, and Priestley's sole reference to data collection (as opposed to data organization and analysis) is to observe that:

\footnotetext{
The first stage of the incident investigation involves obtaining a full description of the sequence of events which led to the failure. This will require interviews with key personnel and examination of the physical evidence in order to piece together the circumstances of the incident (Livingston et al., 2001, p. 4).
}

Implicit in this approach is the assumption that witnesses to an accident act as neutral and accurate recording devices. The role of the investigator is merely to elicit those recordings by asking a comprehensive series of questions covering the 
human, situational, and environmental elements of the situation. We suggest that the burgeoning literature on criminal investigations (e.g., Fisher, 1995), and research on eyewitness testimony (e.g., see reviews by Haber \& Haber, 2000, and Wells \& Olson, 2003 ), casts this assumption into considerable doubt. We now turn to a review of this literature with reference to accident investigation.

\section{ACCIDENTS AS NEGATIVE EMOTIONAL EVENTS}

We begin our analysis with the recognition that a workplace accident ${ }^{3}$ or incident prompting an investigation shares some similarity with the "crime scenes" that have provided the focus for much of the eyewitness literature. The experience of witnessing a crime may be akin to that of witnessing a workplace accident. For eyewitnesses to crimes and workplace accidents, the events are usually unanticipated, can result in death or injury, and are frequently traumatic to both the witnesses and the participants. Christianson (1992, p. 285) describes negative emotional events as "distinct events or scenes that have unpleasant visual features (e.g., blood, injuries) and have the potential to invoke strong unpleasant feelings (emotional stress) in the viewer." Pratt and Barling (1988) referred to such events as acute or catastrophic stressors, having a specific time of onset, a limited duration and evoking intensely negative reactions among the participants/witnesses. Indeed, witnesses to and victims of both violent crimes and workplace accidents may suffer from some form of posttraumatic stress symptoms (e.g., Barling, Bluen, \& Fain, 1987; LeBlanc \& Kelloway, 2002; Rogers \& Kelloway, 1997; Schat \& Kelloway, 2000, 2003; Schooler \& Baum, 1999).

In addition to some topographical similarity between criminal activity and occupational accidents, there is also some similarity in the interviewing process, from the perspective of both the interviewer and interviewee (i.e., the eyewitness). Accident investigations typically include interviews with eyewitnesses or coworkers whose accounts of the events may help investigators identify the factors that caused or contributed to an accident or the severity of the consequences. Criminal investigations share some of the same elements of accident investigations. Law enforcement officers usually gather evidence to find leads and often to determine the identity of the perpetrator; sometimes that evidence includes eyewitness testimony.

As Wells (1995) points out, eyewitness testimony can be compared to other forms of physical evidence because an eyewitness has a memory trace in the brain. Like physical evidence, this memory trace may be altered or destroyed if it is not "handled" properly. Considerable research has now identified factors that affect the integrity of the memory trace in criminal investigations and we suggest that these results have direct implications for occupational accident investigation. We begin our review by discussing the research on the factors that impact eyewitness testimony, identifying the similarities and differences between witnessing aspects of accident

\footnotetext{
${ }^{3}$ The classic definition of an accident is an unplanned and unpredictable event resulting in the loss of property or personal injury. We use this definition recognizing that health and safety professionals now frequently object to the term accident and the inference that such events are unpredictable.
} 
and criminal investigations, and pinpointing the gaps in our knowledge of eyewitness memory that would prevent generalizations to workplace accidents.

\section{FACTORS AFFECTING THE MEMORY TRACE}

To illustrate the importance of eyewitness memory on accident investigations, we point to a report of an airplane crash that killed all nine people aboard. Dozens of bystanders witnessed the crash. One eyewitness insisted at a formal hearing that the airplane nose-dived straight into the ground. By coincidence, several photographs had been taken moments before the crash that proved the airplane coasted down and skidded for nearly 1,000 ft (Flying Magazine, 1977, cited by Loftus \& Doyle, 1997). In this case, the evidence clearly refuted the convinced eyewitness's testimony illustrating our contention that memory for accidents is fallible. Unfortunately, accident investigators rarely have alternative forensic evidence that definitively identifies the precise sequence of events or the cause(s) of the mishap. Moreover, a lack of research attention has resulted in the fallibility of memory being largely overlooked in the health and safety literature.

What we know about eyewitness memory comes from hundreds of studies, most of which attempt to recreate some of these elements by exposing research participants to a staged crime and measuring their memory for the event and perpetrator. Overall, this body of research tells us that eyewitness testimony is not like a videotape recorder; memory is fragile, malleable, and susceptible to forgetting, even in optimal conditions (for reviews see Cutler \& Penrod, 1995; Loftus \& Doyle, 1997; Ross, Read, \& Toglia, 1994). Threats to the accuracy of eyewitness testimony may be present during the encoding or acquisition of the memory (when the eyewitness perceives the event), storage (the time lapse between the event and the subsequent attempt to recall the event), and retrieval (when the eyewitness accesses the memory of the event).

\section{Threats at Encoding}

Several factors can affect eyewitness memory during the encoding of information. Haber and Haber (2000), for example, suggest that encoding of information will be impaired if the witness cannot perceive the event, or is attending elsewhere. Diverse factors may affect the perception of the event. For example, insufficient light obviously impairs the encoding of information, but changes in lighting (from good illumination to poor and vice versa) can also cause difficulties in seeing (Loftus \& Doyle, 1997). Moreover, although researchers have long established that eyewitness accuracy is positively correlated with the duration of the event, people are notoriously poor at estimating the duration of time. Most people overestimate the duration of events. In one study, people estimated the duration of a 30-s mock crime to be nearly 2 min long (on average), and some people even estimated the crime to have lasted over $15 \mathrm{~min}$ (Loftus, Schooler, \& Boone, 1987). People are also poor estimators of distance and speed (Loftus \& Doyle, 1997).

These observations point to the likelihood that witnesses to an occupational accident may not able to provide accurate estimates of time, sequencing, or distances- 
data frequently collected in the course of the investigation (Laing, 1992). Equally troublesome is the notion that witnesses may not be attending to the sequence of events leading up to the accident (Haber \& Haber, 2000). Models of accident causation often invoke the "domino sequence" in which an accident is viewed as the outcome of a sequence of events (Montgomery \& Kelloway, 2002) and the goal of many accident investigations is to recreate this sequence through interviews with the witnesses or victims. This attempt is based on the assumption that witnesses were in fact attending to the relevant events in their environment. Again, the data would suggest that this may not be a reasonable assumption.

In the context of criminal investigations, the presence of a weapon during the commission of a crime tends to direct attention to the weapon rather than on the perpetrator or other factors. Numerous studies and a meta-analytic review confirm that weapon focus clearly impairs memory (Maas \& Kohnken, 1989; Shaw \& Skolnick, 1994; Steblay, 1992). Extrapolating from this data, Haber and Haber (2000) suggest that the presence of a weapon at a crime scene narrows attention and that a similar narrowing of attention will emerge whenever the event is dramatic, violent, or distasteful to the witness. In the case of workplace accidents, it is possible that sudden changes in the environment, or the introduction of a novel stimulus might similarly narrow attention and impair encoding of events in the workplace. For example, consider a hypothetical scenario in which Kay, a control room operator at a manufacturing plant, notices a warning light and siren indicating the overpressurization of a tank. Kay's focus on that warning could impede her ability to notice other signals on the control panel that might indicate another more serious problem is developing. This situation would be exacerbated if control panel malfunctions activate contradictory warning signals to flash (this was the situation that precipitated the crash of Aero Peru Flight \# 603 on October 2, 1996).

Negative emotions and stress reactions often elicited during a crime are also typically present for witnesses to workplace accidents. The emotions elicited by witnessing a workplace accident compared with a crime may be different in some situations, however. Consider the following situation: Joe, who is mopping floors, observes a coworker slip on a wet floor, trip over a bucket of water, fall, and suffer a serious head injury. Joe (our eyewitness) may experience dismay at seeing his coworker's condition, anxiety in finding someone to call for help, and frustration over the ambulance not arriving quickly enough. But Joe may also experience guilt over creating the conditions that contributed to the accident (i.e., failing to alert his coworker that the area was wet or failing to ensure that the floor was dry). He may also experience fear that his carelessness and negligence caused his coworker's injury and that he may lose his job. He may worry that such an accident might happen to him and that he might be similarly debilitating injury. In some situations, eyewitnesses to crimes might experience a similar array of emotions (e.g., consider motor vehicle accidents in which several drivers' errors contributed to a serious accident).

We believe that herein lies one gap in the eyewitness literature; there is a paucity of research that explores the psychological factors (e.g., emotions of guilt, defensive motivations) that are present in real-world events. Indeed, the vast majority of studies in eyewitness memory test eyewitness memory for a stranger's characteristics (i.e., 
facial features) or actions. How does knowing the "players" involved in a crime or accident affect eyewitness memory?

\section{Attitudes, Scripts, and Stereotypes}

Attitudes affect memory in many ways. Making an attitudinal judgment about someone (e.g., determining that Joe is a safe worker) increases the likelihood that attitude-relevant information will be recalled (e.g., he completed the safety checks) and that attitude-consistent inferences will be made (Fiske \& Taylor, 1991). Attitudes affect memory by inducing people to recall the attitude first rather than retrieving and processing all the relevant bits of information about the person (Boon \& Davies, 1988; Loken, 1984). Organizations expend considerable resources in attempts to develop safety consciousness (e.g., safety knowledge and safety behavior) and safety climate (Barling, Loughlin, \& Kelloway, 2002) in the organization and it is conceivable that these attempts affect the encoding of memories about an accident. That is, individuals may be more likely to encode information consistent with the safety climate of the organization or to make inferences consistent with the company's safety culture (Zohar, 1980).

Moreover, there are now data to suggest that experiencing a workplace accident may result in changes in attitudes. Specifically, Barling, Kelloway, and Iverson (2003) found that individuals who had experienced an occupational injury reported a sense of lost control and diminished trust in management. In turn, these attitudes lead to a greater sense of job dissatisfaction and intent to turnover. Similarly, Cree and Kelloway (1997) found that individuals who had experienced a workplace accident subsequently reported a higher perception of risk in the workplace. How quickly these changes in attitudes occur and how they might affect the memory trace remains a question for future research.

A schema is a "cognitive structure that represents knowledge about a concept or type of stimulus, including its attributes and the relations among those attributes" (Fiske \& Taylor, 1991, p. 98). Knowledge about the sequence of events is called a script; people have scripts for numerous activities such as going to the movies. Triggered when people encounter a familiar event, scripts serve to guide expectations, make inferences, process information, and fill in gaps. Reliance on scripts during recall rather than on the original memory trace is more likely when script items are central or highly related to the script and when the retention interval is longer (Greenberg, Westcott, \& Bailey, 1998).

Stereotypes are special schemas about roles that organize people's expectations of people who fit certain groupings (Fiske \& Taylor, 1991). Stereotype-induced expectations influence memory (Allport \& Postman, 1947; Lenton, Blair, \& Hastie, 2001; Sherman \& Bessenoff, 1999, but see Treadway \& McCloskey, 1989 for opposing view). People activate stereotypes at encoding, particularly when their cognitive resources are strained (Sherman \& Bessenoff, 1999). Stereotypes may also affect memory during the retrieval stage (discussed below). In summary, attitudes, scripts, and stereotypes may all contribute to memory errors.

The role of scripts is likely to be especially salient in organizational contexts. Many jobs consist of repetitive actions or familiar sequences of events. These scripts 
of safe work performance may be invoked to fill in gaps in actual memory. This suggestion is consistent with empirical data suggesting that individuals are not able to recall accurately a specific instance of a repeated event (Friedman, 1990; Linton, 1986). Scripts for the "typical" event sequence may be used to fill in the details when recall fails.

With regard to stereotypes, we know that employees are able to make reliable judgments about supervisory, coworker, and managerial commitments to safety and that these perceptions shape employees' own perceptions of risk in the workplace (Cree \& Kelloway, 1997). This suggests the possible influence of stereotyping individuals as being safety conscious or not and gives rise to the possibility that memories may be distorted by the invocation of these same stereotypes. Moreover, a worker's perceptions of risk, coupled with a defensive motivation to feel safe at work may also play a role in a worker's encoding, storage, and retrieval of information related to a workplace accident.

We suggest that the role of attitudes, scripts, and stereotypes on memory for crimes committed by a person unknown to the eyewitness may be different for workplace accident situations. The attitudes of worker-witnesses toward coworkers who were involved in a workplace accident should be better developed, stronger, and more complex than the attitudes of an eyewitness who sees a stranger commit a crime. Workers' greater knowledge of their job should also make them more vulnerable to relying on scripts than eyewitnesses in a criminal setting.

\section{Threats During Storage}

\section{Passage of Time and Postevent Information}

Ordinarily, police officers try to interview eyewitnesses to a crime as soon as possible, but occasionally the interview does not take place for quite some time. Delaying the interview increases the likelihood that postevent information or suggestion will distort eyewitness reports (Hoffman, Loftus, Greenmun, \& Dashiell, 1992). The deleterious effect of delay is exacerbated by the use of leading or suggestive questioning because eyewitnesses are more likely to incorporate the false information into their subsequent reports, particularly when the source of the misinformation is credible (Toland, Hoffman, \& Loftus, 1991). People who witness violent events are particularly susceptible to the deleterious effect of postevent information, presumably because misinformation is less likely to be at odds with the weaker memory trace (Loftus \& Doyle, 1997). Additionally, it is important to note that cognitive processes in eyewitnesses themselves may contribute to the postevent information problem. For instance, because people tend to remember themselves in a favorable light, eyewitnesses' own thoughts and desires may taint their reports (Loftus \& Doyle, 1997). As mentioned earlier, people's sense of responsibility, guilt, and fear may have a similar effect on the memory trace and the subsequent report.

In the context of workplace accidents there is consistent evidence that witnesses to traumatic events experience repetitive, uncontrollable, and intrusive thoughts or memories of the event (see for example, Schooler \& Baum, 1999). Moreover, the 
witness to an accident may be required to repeat his/her version of the events several times to different investigators (e.g., supervisor, health and safety specialist, insurance investigator). There is a substantial body of literature suggesting that such reviews of memory lead to systematic changes in the memory trace and that these changes may be related to the nature or purpose of the review. In particular, Haber and Haber (2000) note that individuals may actively restructure memories on repetition to make sense of seemingly incoherent events.

A related issue involves generating possible causes for an accident. The vast majority of studies looking at the postevent information effect on memory have tested the impact of external sources of postevent information on memory performance (e.g., Loftus \& Palmer, 1974). However, accident investigators, coworkers, and others may ask an eyewitness to a workplace accident to speculate on possible causes. How does the generation of plausible reasons for the event affect the memory trace $?^{4}$ We have found no research on this question.

\section{Factors During Retrieval}

When eyewitnesses attempt to access their memories of the event, several factors may contribute to errors in their testimony or may change their confidence in the accuracy of their testimony.

\section{Stereotypes}

As mentioned above, stereotypes activated during the retrieval stage may contribute to memory errors. When an event is difficult to retrieve, people rely on stereotypes as a backup to "fill in the gaps" (Sherman \& Bessenoff, 1999). Consequently, stereotypes may cause people to attribute stereotype-consistent behaviors to a person and fail to recall stereotype-inconsistent behavior (Sherman \& Bessenoff, 1999).

\section{Interviewing Strategy}

The key to inducing eyewitnesses to recall as much accurate information as possible about the target event lies in the interviewing strategy used by interviewers. The standard police interview tends to consist of a series of closed-ended questions (e.g., "Did he have a weapon?") that are often leading or suggestive (e.g., "The getaway vehicle was a white van, right?"). Numerous studies have shown that the standard police interviewing procedure is far less effective than a psychologically based approach known as the cognitive interview (CI; Fisher, 1995; Fisher, Geiselman, \& Amador, 1989; Fisher, McCauley, \& Geiselman, 1994). The CI allows the eyewitness ample opportunities to recall the event without interruptions, and it also encourages the use of imagery and context-reinstatement. More importantly, the CI elicits more information from the eyewitness without increasing the reporting of incorrect information (Fisher et al., 1994). Thus, the fact that eyewitness reports vary as a function of interviewing technique highlights the importance of optimizing the interviewing conditions.

\footnotetext{
${ }^{4}$ We thank the Editor for this suggestion.
} 
In contrast to typical police procedures, accident investigators are frequently advised to use open-ended questions (e.g., Montgomery \& Kelloway, 2002) although there are no data on how often this advice is followed. However, the popularity of accident causation models and taxonomies of potential causes may lead investigators to focus on some factors to the virtual exclusion of others. The direction of questioning may, therefore, affect the nature of the retrieved memory trace.

\section{Repeated Questioning}

Eyewitnesses to both workplace accidents and crimes are often interviewed repeatedly by several people. Interestingly, repeatedly interviewing eyewitnesses who were wrong about their testimony tends to inflate their confidence in the accuracy of their testimony (Shaw, 1996; Shaw \& McClure, 1996).

\section{Memory Accuracy and Eyewitness Confidence}

Typically, police officers ask eyewitnesses to indicate their level of confidence in the accuracy of their testimony. Most of the literature examines the relation between eyewitness confidence and lineup identification accuracy. These studies tend to show that the confidence-accuracy correlation is small (Sporer, Penrod, Read, \& Cutler, 1995) because there are numerous factors that affect eyewitness confidence (e.g., feedback such as "good, you identified the suspect") that do not affect identification accuracy and vice versa (Wells \& Bradfield, 1998). Feedback confirming eyewitness identifications moderates the relationship by inducing eyewitnesses to report having stronger memories, optimal viewing conditions, and so forth. Note that confirmatory feedback affects people's evaluations of the encoding conditions, precisely the kinds of questions that would be of interest to someone who was evaluating the information provided by eyewitnesses (e.g., lawyers). Thus, when their suspicions are confirmed, investigators may share their excitement with eyewitnesses, thus hopelessly (if inadvertently) tainting the eyewitness' subsequent reports.

Studies examining the relationship between eyewitness confidence and recall accuracy have focused on memory for personal identifying attributes (e.g., age, height, weight; Ebbesen \& Rienick, 1998; Tollestrup, Turtle, \& Yuille, 1994; Yarmey, Jacob, \& Porter, 2002; Yuille \& Cutshall, 1986). In general, these studies reveal a small to moderate correlation between eyewitness confidence and accuracy of memory for criminal events (Yarmey, 1993; Yarmey, Jacob, \& Porter, 2002). We have found no research examining the eyewitness confidence-accuracy correlation in workplace accidents. We propose that eyewitness confidence may affect workplace accident investigations in at least three ways. First, accident investigators may weigh the reports of more confident eyewitnesses more heavily than those of less confident eyewitnesses. Of course, there is no problem if the memories of highly confident eyewitnesses are correct; difficulties could arise when highly confident eyewitnesses are incorrect in their testimony. ${ }^{5}$ Most investigations are conducted by individuals with little training in proper investigative or interviewing techniques (Ferry, 1998). It is highly unlikely that they have any special training on the psychology of memory

\footnotetext{
${ }^{5}$ We focus our attention here on memory issues, not on situations in which eyewitnesses to workplace accidents intentionally distort their reports)
} 
and decision-making; it is far more likely that investigators share many of the misconceptions about eyewitness memory. Most people believe in a positive eyewitness confidence-accuracy correlation, and most believe that our memories for events are stable over time (i.e., do not decline; Haber \& Haber, 2000). Second, giving undue weight to the testimony of highly confident eyewitnesses may lead accident investigators to change the nature of their search for information. They may disregard once-plausible explanations for the accident or change the direction of their investigation. Finally, other eyewitnesses to the event may be more vulnerable to suggestibility effects when exposed to the reports of highly confident eyewitnesses. This effect may be especially true in a workplace setting where employees are typically well-known to each other.

\section{Investigative Procedures and Context}

Clearly, eyewitness memory is not perfect; it is susceptible to the influence of numerous factors that usually decrease rather than increase the accuracy of the testimony. Accident investigators rely on employee eyewitness accounts, so accident eyewitness reports should be susceptible to the same problems. How do accident investigators actually handle memory evidence in their analysis of the event? We know of no research exploring this question, but criminal investigations may shed some light into this issue.

Unlike most employees who conduct accident investigators, police officers are highly trained in matters dealing with the handling of physical evidence. Officers are instructed to follow strict science-based procedures when handling physical evidence. Law enforcement training and protocol relating to eyewitness testimony is far more rudimentary; most police officers have little understanding of memory processes and the social-cognitive factors that affect it (Wells \& Loftus, in press). Given the lack of specific training in investigative techniques (Laing, 1992), accident investigators are probably similarly ignorant of these psychological processes.

Interestingly but not surprisingly, health and safety professionals have made interviewing recommendations that either contradict or are unsupported by psychological research. For example, accident investigators are advised to interview first people who were not directly involved in the incident (e.g., senior management) so that the investigator has a good idea of what happened (Ammerman, 1998). This strategy has at least three drawbacks. First, it provides the investigator with schemas that will influence the both the investigator's understanding of the incident and his or her subsequent interviews with the key players involved. ${ }^{6}$ Second, delaying the interviews with those who were directly involved provides more opportunities for postevent information and contamination from other witnesses, supervisors, etc. to impair their memories; the effect of postevent information is positively correlated with the duration of the retention interval (Belli, Windschitl, McCarthy, \& Winfrey, 1992). Finally, knowing that the investigator consulted with senior management first may increase the stress and fear of those who were directly involved in the incident. Their motivation to defend their actions (or inactions), defend the actions or inac-

\footnotetext{
${ }^{6}$ Of course, there is no problem if the schemas are accurate. The difficulty arises when the schemas are
} wrong because it is difficult to change schemas (see Fiske \& Taylor, 1991, for a review). 
tions of respected coworkers, and provide a clear and complete description of the events preceding and following the incident will be affected.

Another interviewing strategy that seems at odds with psychological research is the use of "ok," "uh huh," and "okay" during interviews. Ammerman (1998) advocates the use of such expressions to convey the "impression of responsiveness and attentiveness" (p. 55). Psychological research would caution against the use of these expressions because they may convey approval of the eyewitness' testimony and encourage the eyewitness to provide testimony that elicits the same approval.

The criminal investigations involving eyewitnesses may also be different from occupational/workplace accident investigations in several respects. Most eyewitnesses sincerely try to help police investigators and do not deliberately distort their reports (Wells, 1993). The same may not be true for witnesses to workplace accidents. Coworkers who witnessed an accident may intentionally cover up for a victim. This is particularly likely in organizational contexts that penalize unsafe work performance. Just as government sanctions might lead organizations to underreport accidents and injuries, organizational sanctions may lead individuals to suppress or distort their reports of accidents.

There are some data to support this suggestion. Reason, Parker, and Lawton (1998) note that management may well react to injuries, especially serious injuries, by tightening their use of procedures and rules, thereby exerting greater control. In their development of an accident reporting system for the offshore oil industry, Gordon, Mearns, Flin, O'Connor, and Whitaker (2000, p. iii) reported that "The main problem in gathering human factors causal data was respondents' reluctance to given open and candid responses to the forms."

Unlike in many real life situations, the research models used in the eyewitness memory literature reflect the assumption that there is a single "truth" (e.g., the perpetrator committed the robbery or the vehicle failed to yield to the oncoming car). Indeed, most experiments on eyewitness memory involve the use of one perpetrator (for exceptions, see Clifford \& Hollin, 1981; Geiselman, MacArthur, \& Meerovitch, 1993). In contrast, workplace accidents are usually much more complex and focus on "why" events occurred rather than just "what" events occurred in a specific incident.

For example, the theory of normal accidents (Perrow, 1984, 1994) particularly in high reliability organizations (e.g., chemical plants, nuclear plants; Weick, Sutcliffe, \& Obstfield, 1999) suggests that accidents result from the interactive complexities in the technological system. That is, there is no single event that causes an accident and the search for a single discrete cause, analogous to a single perpetrator, might well be fruitless in such an environment. The futility of the endeavor may be difficult to recognize given the common tendency to make sense out of organizational events. As Weick (1995, p. 28) notes "people who know the outcome of a complex prior history of tangled, indeterminate events, remember that history as being much more determinant, leading 'inevitably' to the outcome they already knew."

In many workplace accidents the actions or inactions of the accident victim and other coworkers may contribute to the event. The eyewitnesses are usually coworkers who know the victim, so schemas, expectations, and affect may affect memory (Fiske \& Taylor, 1991). Information that is consistent with a schema is more likely to be recalled than information that is deemed to be irrelevant (Fiske \& Taylor, 1991), 
so office politics may shape the witnesses' subsequent memories of the incident and attributions of responsibility. Organizational safety culture (Zohar, 1980) may also play a role in shaping the witnesses' memories of the incident and their attributions of responsibility. Moreover, adverse consequences for employees who were involved in a workplace mishap may shape both their reports and those of their coworkers. Research tells us that people tend to remember more information about in-group members than out-group members, and they tend to recall more negative information about out-group members (Fiske \& Taylor, 1991). Other factors, such as union membership (Kelloway, in press), may contribute to the eyewitnesses and victim adopting a particular perspective and recalling only certain aspects of the event.

Given considerable ambiguity inherent in assigning causality for a workplace accident, attributional errors are likely. Defensive attribution refers to the notion that people will assign greater responsibility to people when their actions lead to severe rather than minor consequences (Shaver, 1970). However, people tend to attribute less responsibility to an accident perpetrator whose actions lead to serious consequences when they are similar to the perpetrator. When people are dissimilar to an accident perpetrator whose actions lead to severe consequences, they tend to attribute more responsibility to the perpetrator. Defensive attributions also affect eyewitness recall memory and related judgments in a way that reduces the perceived threat of seeing someone similar to the eyewitness be a crime victim (Marsh, 1997). Although we have found no empirical research supporting this notion, defensive attributions might explain why employees tend to place blame for their injuries on management. The fundamental attribution error refers to the tendency for people to attribute other people's behavior to internal stable factors (e.g., personality) and to underestimate the role of external situational factors (Fiske \& Taylor, 1991). It leads to the prediction that employees will assign blame for their injuries to managers. In both cases, the role of personal and situational factors would be minimized (Hofmann \& Stetzer, 1998). Clarke (1999) for example, found that train drivers erroneously estimated that their supervisors and managers had less knowledge, and cared less about occupational safety than they actually did.

Eyewitnesses are not the only ones who are affected by schemas and expectations. Like law enforcement officers who sometimes have a suspect in mind when they interview eyewitnesses, accident investigators often expect the accident victim to be at fault for the workplace accident. This bias probably induces investigators to look for information that confirms their hypothesis regarding the cause of the accident and ignore other potentially relevant information. This is particularly troublesome in light of the often-cited, but rarely substantiated, claim that "Human error is the cause of most accidents" (Dekker, 2002, p. 372). As Dekker (2002, p. 372) notes "An investigators' emphasis on proximal causes ensures that the mishap remains the result of a few uncharacteristically ill-performing individuals who are not representative... of the larger population." These expectations probably guide their search for evidence as well as their analysis of the information gleaned. Thus, most investigators (both police and accident) don't realize that their expectations guide their thinking about their case. The tunnel vision problem is serious, so much so that investigation reports of wrongful convictions have advised police departments to provide annual training to police officers (www.gov.mb.ca/justice/sophonow). 
There is one aspect of accident investigations that differs from that of police investigations. In accident investigations, managers typically have the responsibility of investigating accidents. Because managers are ultimately responsible for anything that happens on their watch, they have a personal role in the investigation. As Vincoli (1993) points out, "the fact that an accident occurs is a strong indication that a manager somewhere within the organization has made a bad decision" (p. 11; e.g., a floor manager may have erred in the job assignment, there was some miscommunication regarding the proper use of equipment, etc.). Thus, accident investigators have a vested interest in the outcome of their investigation. They will be motivated to find that the accident was, for example, due to employee carelessness and not to some factor under the control and responsibility of the manager. Police investigators are certainly motivated to solve crimes, but their investigations do not typically involve inquiries into their own shortcomings or errors.

\section{IMPLICATIONS FOR RESEARCH}

Perhaps the most striking implication of our review is the obvious need for more research on workplace accident investigations. Although there are many manuals and instructional guides telling investigators "what" to look for in conducting an accident investigation, the almost universal assumption is that witnesses and victims who might be interviewed are both (a) capable of recalling the exact sequence of events, and (b) willing and capable of disclosing all relevant information. Indeed in preparing this paper we consulted a colleague who specializes in health and safety and were promptly informed that we were off track because "everyone knows what happened" in any given accident. We know of no data that would justify this position and have reviewed a number of studies conducted in the context of criminal investigations that would suggest otherwise.

We suggest that a more fruitful starting point is to recognize that the process of investigation is an attempt to retrieve a memory trace (Wells, 1995) and that memory is fragile, malleable, and susceptible to forgetting, even in optimal conditions. Starting from this position points to the need to identify the factors that may distort or change individual memories of the event. In the long run, such research would also point to more effective investigative techniques. We believe that some of the data collected in the study of criminal investigations should readily transfer to the health and safety setting allowing researchers to build on a considerable body of empirical data that has already accumulated.

We suggest that a starting point for a research agenda on accident investigation is to explore the accuracy of eyewitness testimony in this context. Noting that accidents often unfold over a considerable period of time and are rarely preceded by unusual events that would act as warning signs (Dekker, 2002) the conditions for eyewitness accuracy would seem to be suboptimal. However, given the absence of empirical evidence on accident investigations, we believe there is some value to research simply demonstrating the generalizability of eyewitness findings to this new domain.

In identifying workplace accident investigations as a focal point for future research, we believe that there is an opportunity to test the generalizability of findings 
from the forensic setting. Much of the research we reviewed has been based on simulated or actual crime settings. Although this is an appropriate focus given the intent of the research, reliance on a small set of situations gives rise to the possibility of constructing and disseminating a truncated body of knowledge. We have proposed that workplace accident investigation may provide an analogue to criminal settings and that both health and safety and forensic researchers would benefit from expanding the research focus in this way.

In our analysis of the eyewitness literature and the "practice" of accident investigations we identified several variables that should be studied further and several questions that researchers could address. First, in accident investigations the eyewitnesses may (a) know the victims and perpetrators (if any), (b) have well-established scripts for how these individuals perform tasks in the workplace on a day-to-day basis, and (c) experience emotional states such as guilt or fear. In brief, eyewitnesses to accidents are intimately connected to the individuals and events involved. How does this level of connection (which may also be present in some criminal investigations) affect eyewitness testimony?

Second, there are good grounds to suggest that (a) individuals actively sort through and reorganize information to make sense of complex information (e.g., Dekker, 2002; Weick, 1995); (b) accidents are most likely the result of multiple causes (e.g., Perrow, 1984) some of which may not be readily observable; and (c) there is a tendency for accident witnesses and investigators to blame individual rather than system causes (e.g., Dekker, 2002). There is also a tendency for eyewitnesses to cognitively restructure the event witnessed to place some distance from the victim and reduce threat (Janoff-Bulman, 1982). Is there a bias toward identifying a perpetrator in accident investigations? If so, how does this impact on eyewitness testimony?

Third, what is the impact of having investigations conducted by managers who might bear some responsibility for the incident under investigation? How does management style, or management reaction to an accident, affect eyewitness accounts? Does a punitive management style result in distorted accounts?

Finally, does the extensive research database on eyewitness testimony in criminal investigations provide grounds for improving eyewitness testimony in accident investigations? Do techniques such as the Cognitive Interview or other interviewing techniques result in more detailed, more accurate, or less biased eyewitness accounts?

Accident investigations have as their primary purpose to find out why accidents occurred and to prevent similar accidents in the future. We suggest that this goal is unlikely to be achieved if investigations are predicated on unrealistic assumptions about the quality of the data. Assessment of the accident investigation process and development of more effective techniques are a suitable focus for future research. It is our hope that this review might stimulate research in this area.

\section{ACKNOWLEDGMENTS}

Preparation of this paper was supported by grants from the Social Sciences and Humanities Research Council of Canada and the Nova Scotia Health Research foundation to the first author. 


\section{REFERENCES}

Allport, G. W., \& Postman, L. J. (1947). The psychology of rumor. Oxford, England: Holt.

Ammerman, M. (1998). The Root Cause Analysis Handbook. NY: Productivity Inc.

Barling, J., Bluen, S. D., \& Fain, R. (1987). Psychological functioning following an acute disaster. Journal of Applied Psychology, 72, 683-690.

Barling, J., Kelloway, E. K., \& Iverson, R. (2003). Accidental outcomes: Attitudinal consequences of workplace injuries. Journal of Occupational Health Psychology, 8, 74-85.

Barling, J., Kelloway, E. K., \& Zacharatos, A. (2002). Occuptional safety. In P. B. Warr (Ed.), Psychology at work (5th ed). London: Penguin.

Barling, J., Loughlin, C., \& Kelloway, E. K. (2002). Development and test of a model linking safety-specific transformational leadership and occupational safety. Journal of Applied Psychology, 87, 488-496.

Belli, R. F., Windschitl, P. D., McCarthy, T. T., \& Winfrey, S. E. (1992). Detecting memory impairments with a modified test procedure: Manipulating retention interval with centrally presented event items. Journal of Experimental Psychology: Learning, Memory, and Cognition, 18, 356-367.

Boon, J. C. W., \& Davies, G. (1988). Attitudinal influences on witness memory: Fact and fiction. In M. M. Gruneberg, P. E. Morris, \& R. N. Sykes (Eds.), Practical aspects of memory: Current research and issues (Vol. 1, pp. 53-58). New York: Wiley.

Christianson, S. A. (1992). Emotional stress and eyewitness memory: A critical review. Psychological Bulletin, 112, 284-309.

Clarke, S. (1999). Perceptions of organizational safety: Implications for the development of safety culture. Journal of Organizational Behavior, 20, 185-198.

Clifford, B. R., \& Hollin, C. R. (1981). Effects of the type of incident and number of perpetrators on eyewitness memory. Journal of Applied Psychology, 66, 364-370.

Conway, H., \& Svenson, J. (1998). Occupational injury and illness rates 1992-1996: Why they fell. Monthly Labor Review, 121, 36-58.

Cree, T., \& Kelloway, E. K. (1997). Responses to occupational hazards: Exit and participation. Journal of Occupational Health Psychology, 2, 304-311.

Cutler, B. L., \& Penrod, S. D. (1995). Mistaken identification: The eyewitness, psychology, and the law. New York: Cambridge University Press.

Dekker, S. W. A. (2002). Reconstructing human contribution to accidents: The new view on error and performance. Journal of Safety Research, 33, 371-385.

Dupré, D. (2000). Accidents at work in the E.U. in 1996. Statistics in focus: Population and Social Conditions, 3(4), 1-7.

Ebbesen, E. B., \& Rienick, C. B. (1998). Retention interval and eyewitness memory for events and personal identifying attributes. Journal of Applied Psychology, 83, 745-762.

Eisenberg, W. M., \& MacDonald, H. (1988). Evaluating workplace injury and illness records: Testing a procedure. Monthly Labor Review, 111, 58-60.

Ferry, T. D. (1988). Modern accident investigation and analysis (2nd ed). New York: Wiley.

Fisher, R. P. (1995). Interviewing victims and witnesses of crime. Psychology, Public Policy, and Law, 1, $732-764$.

Fisher, R. P., Geiselman, R. E., \& Amador, M. (1989). Field test of the cognitive interview: Enhancing the recollection of actual victims and witnesses of crime. Journal of Applied Psychology, 74, 722-727.

Fisher, R. P., McCauley, M. R., \& Geiselman, R. E. (1994). Improving eyewitness testimony with the Cognitive Interview. In D. F. Ross, J. D. Read, \& M. P. Toglia (Eds.), Adult eyewitness testimony: Current trends and developments (pp. 245-272). New York: Cambridge University Press.

Fiske, S. T., \& Taylor, S. E. (1991). Social Cognition (2nd ed.). New York: McGraw-Hill.

Friedman, W. J. (1990). About time. Cambridge, MA: MIT Press.

Geiselman, R. E., MacArthur, A., \& Meerovitch, A. (1993). Transference of perpetrator roles in eyewitness identifications from photoarrays. American Journal of Forensic Psychology, 11(4), 5-15.

Gordon, R., Mearns, K., Flin, R., O'Connor, P., \& Whitaker, S. (2000). Factoring the Human into Safety: Translating Research into Practice. Vol 2: The Development and evaluation of a human factors accident and near miss reporting form for the offshore oil industry. Aberdeen, UK: University of Aberdeen.

Greenberg, M. S., Westcott, D. R., \& Bailey, S. E. (1998). When believing is seeing: The effect of scripts on eyewitness memory. Law and Human Behavior, 22, 685-694.

Haber, R. N., \& Haber, L. (2000). Experiencing, remembering and reporting events. Psychology, Public Policy, and Law, 6, 1057-1097.

Hoffman, H. G., Loftus, E. F., Greenmun, N., \& Dashiell, R. L. (1992). The generation of misinformation. In F. Losel, D. Bender, \& T. Bliesener (Eds.), Psychology and law: International perspectives (pp. 292 301). Berlin: Walter de Gruyter. 
Hofmann, D. A., \& Stetzer, A. (1998). The role of safety climate and communication in accident interpretation: Implications for learning from negative events. Academy of Management Journal, 41, 644-657.

Janoff-Bulman, R. (1982). Esteem and control bases of blame: "Adaptive" strategies for victims versus observers. Journal of Personality, 50, 180-192.

Kelloway, E. K. (2003). Labor unions and occupational safety: Conflict and cooperation (pp. 249-264). In J. Barling \& M. Frone (Eds.), Psychology of occupational safety. Washington, DC: APA Books.

Laing, P. (1992). Accident prevention manual for business and industry: Administration and programs (10th ed.). Washington, DC: National Safety Council.

LeBlanc, M., \& Kelloway, E. K. (2002). Predictors and outcomes of workplace violence and aggression. Journal of Applied Psychology, 87, 444-453.

Leigh, J. C., Markowitz, S. B., Fah, M., Shin, C., \& Landrigan, P. J. (1997). Occupational injury and illness in the U.S.: Estimates of cost, morbidity, and mortality. Archives of Internal Medicine, 157, 1557-1568.

Lenton, A. P., Blair, I. V., \& Hastie, R. (2001). Illusions of gender: Stereotypes evoke false memories. Journal of Experimental Social Psychology, 37, 3-14.

Linton, M. (1986). Ways of searching and the contents of memory. In D. C. Rubin (Ed.), Autobiographical memory (pp. 50-67). New York: Cambridge University Press.

Livingston, A. D., Jackson, G., \& Priestley, K. (2001). Root causes analysis: Literature review. Contract Research Report 325/2001. London, UK: Health and Safety Executive.

Loftus, E. F., \& Doyle, J. M. (1997). Eyewitness testimony: Civil and criminal (3 rd ed). Charlottesville, VA: Lexis Law.

Loftus, E. F., \& Palmer, J. C. (1974). Reconstruction of automobile destruction: An example of the interaction between language and memory. Journal of Verbal Learning and Verbal Behavior, 13, 585589.

Loftus, E. F., Schooler, J. W., \& Boone, S. M. (1987). Time went by so slowly: Overestimation of event duration by males and females. Applied Cognitive Psychology, 1, 3-13.

Loken, B. (1984). Attitude processing strategies. Journal of Experimental Social Psychology, 20, $272-296$.

Maas, A., \& Kohnken, G. (1989). Eyewitness identification: Simulation the "weapon effect." Law and Human Behavior, 13, 397-408.

Marsh, D. P. (1997). Defensive attribution, witness' similarity to the victim of a criminal incident, and implications for the witness' recall of the incident. Unpublished doctoral dissertation, University of Pittsburgh, CA.

Marshall, K. (1996, Summer). A job to die for. Perspectives on Labour and Income. 26-31.

Montgomery, J., \& Kelloway, E. K. (2002). Management of occupational health and safety, (2nd ed.). Toronto: Nelson.

Perrow, C. (1984). Normal accidents: Living with high-risk technologies. New York: Basic Books.

Perrow, C. (1994). Accidents in high risk systems. Technological Studies, 1, 1-20.

Pratt, L. I., \& Barling, J. (1987). Differentiating between daily events, acute and chronic stressors: A framework and its implications. In J. R. Hurrell, L. R. Murphy, S. L. Sauter, \& C. L. Cooper (Eds.) Occupational stress: Issues and developments in research (pp. 41-53). London: Taylor \& Francis.

Reason, J. (1990). Human error. Cambridge, UK: Cambridge University Press.

Reason, J., Parker, D., \& Lawton, R. (1998). Organizational controls and safety: The varieties of rulerelated behaviour. Journal of Occupational and Organizational Psychology, 71, 289-304.

Roberts, K. (1989). Some characteristics of high reliability organizations. Organization Science, 2, 160176.

Rogers, K., \& Kelloway, E. K. (1997). Violence at work: Personal and organizational outcomes. Journal of Occupational Health Psychology, 2, 63-71.

Ross, D. F., Read, J. D., \& Toglia, M. P. (1994). Adult eyewitness testimony: Current trends and developments. New York: Cambridge University Press.

Ryan, T. (1991). Accident investigations: Group investigations. In F. Briggs (Ed.), Guide to health and safety management. Don Mills, ON: Southam Business.

Sauter, S. L., Hurrell, J. J., Fox, H., Tetrick, L. E., \& Barling, J. (1999). Occupational health psychology: An emerging discipline. Industrial Health, 37, 199-211.

Schat, A., \& Kelloway, E. K. (2000). Effects of perceived control on the outcomes of workplace aggression and violence. Journal of Occupational Health Psychology, 5, 386-402.

Schat, A., \& Kelloway, E. K. (2003). Reducing the adverse consequences of workplace aggression and violence: The buffering effects of organizational support. Journal of Occupational Health Psychology, $8,110-122$.

Schooler, T. Y., \& Baum, A. (1999). Memories of a petrochemical explosion: A cognitivephenomenological study of intrusive thoughts. In L. Williams and V. L. Banyard (Eds.), Trauma \& memory (pp. 189-201). Thousand Oaks, CA: Sage. 
Shaver, K. G. (1970). Defensive attribution: Effects of severity and relevance on the responsibility assigned for an accident. Journal of Personality and Social Psychology, 14, 101-113.

Shaw, J. S., III (1996). Increases in eyewitness confidence resulting from postevent questioning. Journal of Experimental Psychology: Applied, 2, 126-146.

Shaw, J. S., \& McClure, K. (1996). Repeated postevent questioning can lead to elevated levels of eyewitness confidence. Law and Human Behavior, 20, 629-653.

Shaw, J. I., \& Skolnick, P. (1994). Sex differences, weapon focus, and eyewitness reliability. Journal of Social Psychology, 134, 413-420.

Sherman, J. W., \& Bessenoff, G. R. (1999). Stereotypes as source-monitoring cues: On the interaction between episodic and semantic memory. Psychological Science, 10, 106-110.

Sporer, S. L., Penrod, S. D., Read, J. D., \& Cutler, B. L. (1995). Choosing, confidence, and accuracy: A meta-analysis of the confidence-accuracy relation in eyewitness identification studies. Psychological Bulletin, 118, 315-327.

Statistics Canada. (1994). Work injuries 1991-1993 (Cat. No. 72-208). Ottawa, Canada.

Steblay, N. M. (1992). A meta-analytic review of the weapon focus effect. Law and Human Behavior, 16, $413-424$

Toland, K., Hoffman, H., \& Loftus, E. F. (1991). How suggestion plays tricks with memory. In J. F. Schumaker (Ed.), Human suggestibility: Advances in theory, research, and application (pp. 235-252). New York: Routledge.

Tollestrup, P. A., Turtle, J. W., \& Yuille, J. C. (1994). Actual victims and witnesses to robbery and fraud: An archival analysis. In D. F. Ross, J. D. Read, \& M. P. Toglia, (Eds.), Adult eyewitness testimony: Current trends and developments (pp.144-162). New York: Cambridge University Press.

United States Census Bureau (2000). Statistical Abstract of the United States. Washington DC.

Vincoli, J. W. (1993). Basic Guide to System Safety. New York: Wiley.

Weick, K. (1995). Sensemaking in organizations. Thousand Oaks, CA: Sage.

Weick, K. E., Sutcliffe, K. M., \& Obstfeld, D. (1999). Organizing for high reliability: Processes of collective mindfulness. Research in Organizational Behavior, 21, 81-123.

Wells, G. L. (1993). What do we know about eyewitness identification? American Psychologist, 48, 553-571.

Wells, G. L. (1995). Scientific study of witness memory: Implications for public and legal policy. Psychology, Public Policy, and Law, 1, 726-731.

Wells, G. L., \& Bradfield, A. L. (1998). "Good, you identified the suspect": Feedback to eyewitnesses distorts their reports of the witnessing experience. Journal of Applied Psychology, 83, 360-376.

Wells, G. L., \& Loftus, E. F. (in press). Eyewitness memory for people and events. In A. Goldstein (Ed.), Comprehensive handbook of psychology. Vol. 11: Forensic psychology. New York: Wiley.

Wells, G. L., \& Olson, E. A. (2003). Eyewitness testimony. Annual Review of Psychology, 54, 277-295.

Yarmey, A. D. (1993). Adult age and gender differences in eyewitness recall in field settings. Journal of Applied Social Psychology, 23, 1921-1932.

Yarmey, A. D., Jacob, J., \& Porter, A. (2002). Person recall in field settings. Journal of Applied Social Psychology, 32, 2354-2367.

Yuille, J. C., \& Cutshall, J. L. (1986). A case study of eyewitness memory of a crime. Journal of Applied Psychology, 71, 291-301.

Zohar, D. (1980). Safety climate in industrial organizations: Theoretical and applied implications. Journal of Applied Psychology, 65, 96-102. 